\title{
Correction: Weight gain during pregnancy: Does the antenatal care provider make a difference? A retrospective cohort study
}

Errors occurred in an article published Apr. 23, 2019. ${ }^{1}$ The labels "Adjusted RR (95\% CI)" in Figures 5 and 6 should have been "Population attributable fraction (95\% CI)."

CMAf Open apologizes for the errors, which have been corrected at cmajopen.ca.

\section{Reference}

1. Murray-Davis B, Berger H, Melamed N, et al.; for the Diabetes, Obesity and Hypertension in Pregnancy Research Network and Southern Ontario Obstetrical Network investigators. Weight gain during pregnancy: Does the antenatal care provider make a difference? A retrospective cohort study. CMAF Open 2019;7:E283-93.

CMAJ Open 2019. DOI:10.9778/cmajo.20190066 